\title{
Studying the Properties of PVdF-HFP Based Lithium Polymer Electrolytes Using non-ionic Surfactants as Plasticizers
}

\author{
LEIRE ZUBIZARRETA ${ }^{1 *}$, MAYTE GIL-AGUSTI ${ }^{1}$, JUAN CARLOS ESPINOSA, \\ MARTA GARCIA-PELLICER ${ }^{1}$, ALFREDO QUIJANO-LOPEZ ${ }^{2}$ \\ ${ }^{1}$ Instituto Tecnológico de la Energía (ITE), Avenida Juan de la Cierva, 2446980 Paterna, Valencia, Spain \\ ${ }^{2}$ Universitat Politècnica de València. Camino de Vera, s/n - 46022 Valencia
}

\begin{abstract}
In this study, two different non-ionic surfactants have been evaluated as a plasticizer in lithium polymer electrolytes and compared with an organic carbonate-based plasticizer. To that end, non-ionic surfactants with different molecular weight and structure have been selected (Triton ${ }^{\circledR}$ X-100 and Brij ${ }^{\circledR}$ L23) and compared with organic carbonates (EC:DEC1:1) as plasticizers in lithium polymer electrolytes. The effect of the plasticizer content, salt content and surfactant characteristics on properties such as ionic conductivity, thermal stability and electrochemical stability of lithium polymer electrolytes has been studied. The results obtained show that the non-ionic surfactants studied as plasticizers (Triton ${ }^{\circledR}$-100 and Brij®L23) give lithium polymer electrolytes with higher thermal and electrochemical stability than organic carbonates, thus making them promising plasticizers for lithium polymer electrolytes, especially for high voltage lithium-ion batteries. Surfactant structure could influence the ionic conductivity of the polymer electrolytes, with the linear surfactants being more suitable for this application.
\end{abstract}

Keywords: polymer electrolyte, surfactant, lithium battery, plasticizer, PVdF-HFP

\section{Introduction}

It is worth noting that the limited energy density of lithium-ion batteries (LIB) is strongly associated with the organic liquid electrolyte, as well as potential safety risks. To address these limitations two strategies are needed: the use of high energy voltage cathode materials and the replacement of the organic liquid electrolyte by a non-flammable, safe and highly reliable electrolyte [1,2]. The fact that conventional carbonate solvent-based electrolytes exhibit an inferior anodic stability of less than $4.3 \mathrm{~V}$ vs $\mathrm{Li} / \mathrm{Li}+$ and the mitigation of the undesirable oxidative decomposition of electrolytes become the decisive factors restricting electrode capacity of high-voltage LIBs [3]. This issue has gained much attention from both academia and industry as advanced LIBs should cover a combination of high-voltage cathodes, high-capacity anodes and the corresponding high-voltage electrolytes.

Polymer electrolytes are promising materials for next-generation lithium batteries [4]. Since Armand first proposed the first PEO/Li+ polymer electrolyte system $\left(\sim 10^{-5} \mathrm{~S} \mathrm{~cm}^{-1}\right.$ at $\left.40-60^{\circ} \mathrm{C}\right)$ for lithium batteries in 1978 [5], polymer electrolytes have attracted widespread attention due to their superior features such as free-standing, shape versatility, security, flexibility, lightweight, and reliability.

However, the wide range applications of polymer electrolytes in commercial LIBs still have a long way to go owing to low ionic conductivity (mostly ranging from $10^{-8}$ to $10^{-5} \mathrm{~S} \mathrm{~cm}^{-1}$ at room temperature), low electrochemical stability and high working temperature [6]. Several strategies aimed at improving room temperature conductivity while preserving the inherent advantages of polymers have been explored over the last two decades. In order to solve this problem, different methods have been proposed by several research teams; such as cross-linking polymers [7], introducing polymers into side chains to make them a comb shape [8], and the addition of plasticizers $[9,10]$.

Among these approaches, plasticized polymer electrolytes are regarded as a prospective alternative for traditional liquid electrolytes used in batteries. This fact is related to the cohesive properties of solids and the better diffusive properties in contrast to unplasticized polymer electrolytes.

$\overline{\text { email:leire.zubizarreta@ite.es }}$ 
Different plasticized lithium polymer electrolytes have been studied based on polymer matrices such as PEO, PAN, PMMA, PVC, PVdF [10]. Among the ionic conducting polymers, PVdF-HFP copolymer was found to meet all the requirements for use as the polymer host in plasticized polymer electrolytes in terms of electrochemical stability, performance, processability, and safety. PVdF-HFP contains amorphous domains (HFP) capable of trapping large amounts of plasticizer, and crystalline regions $(\mathrm{VdF})$ which provide chemical stability and suitable mechanical integrity for the processing [11].

Concerning the plasticizers, the most common approach is based on low molecular weight liquids such as ethylene carbonate (EC), propylene carbonate (PC), dimethylformamide (DMF), diethyl phthalate (DEP), diethyl carbonate (DEC), etc. These plasticizers increase the flexibility of the polymer chain and enhance ionic conductivity. The effect of plasticizer on the polymer electrolyte strongly relies on the specific nature of the plasticizer, including dielectric constant, polymer-plasticizer interaction and ion plasticizer coordination [12]. However, the electrochemical stability of these plasticized polymer electrolytes is still low (4.3 V vs $\mathrm{Li} / \mathrm{Li}+)$ associated with the low electrochemical stability of the plasticizers used.

Surfactants form a unique class of chemical compounds. The widespread importance of surfactants in practical applications and scientific interest in their nature and properties has precipitated a wealth of literature published on the subject. Although surfactant science is now a reasonably mature discipline, there is still room for new molecules designed for specific purposes and new applications (such as nanoparticle synthesis and more diverse and environmentally-friendly consumer products). Polymers and surfactants are widely used in many commercial formulations [13]. One of the applications of surfactants in polymer science is their use as a plasticizer to improve the different properties of polymer matrices [14].

In the area of lithium polymer electrolyte, few research studies have been performed. Surfactants such as PEG $[15,16]$ and PEGDME $[4,17]$ have been used as plasticizers for this purpose and show a good ability to improve the ionic conductivity of polymer electrolytes. However, their effect on other relevant properties such as electrochemical and thermal stability, and ionic conductivity has not been fully studied. Additionally, taking into account the great variety of different kinds of surfactants, their effect on lithium polymer membrane development needs further study.

In this context, this paper aims to study the effect of two different non-ionic surfactants (Triton® X100 and Brij®L23) as a plasticizer on different properties (i.e. ionic conductivity, electrochemical and thermal stability) of PVdF-HFP based-polymer electrolytes.

\section{Materials and methods}

\subsection{Preparation of lithium polymer electrolytes}

For the synthesis of polymer electrolytes, the following materials were used: PVdF-HFP $(\mathrm{Mw}=400.000)$, Ethylene carbonate (EC), Diethyl carbonate (DEC), Triton ${ }^{\circledR} \mathrm{X}-100$, Brij ${ }^{\circledR L} 23$, Tetrahydrofuran (THF) from Sigma-Aldrich, and LiPF6 from Fluorochem.

Several lithium polymer electrolytes were prepared using the different plasticizers selected for this study. The same composition was fixed for all of them as can be seen in Table 1. The solution casting technique was used to obtain the polymer membranes. Firstly, all the components (polymer, lithium salt and plasticizer) were dissolved by stirring at $60^{\circ} \mathrm{C}$ in a sealed glass tube. The mixture obtained was cast using an Automatic Film Applicator (BYK) set at $50 \mathrm{~mm} / \mathrm{s}$ speed and fixing a casting knife of $500 \mu \mathrm{m}$. Finally, the solvent was evaporated at room temperature. All the steps in processing materials were performed under a dry atmosphere. The thickness of the obtained films was measured using a micrometre screw gauge. Results of measurements of lithium polymer electrolytes were found to be around $50 \mu \mathrm{m}$. 
Table 1. Nomenclature and composition of synthesized polymer membranes

\begin{tabular}{|c|c|c|c|c|}
\hline Sample & Plasticizer & $\begin{array}{c}\text { PVdF-HFP } \\
\text { (wt.\%) }\end{array}$ & $\begin{array}{l}\text { Lithium salt } \\
\text { (wt.\%) }\end{array}$ & $\begin{array}{c}\text { Plasticizer } \\
\text { (wt.\%) }\end{array}$ \\
\hline A0 & - & 100 & 0 & 0 \\
\hline $\mathbf{A 1}$ & EC:DEC (1:1) & 55 & 15 & 30 \\
\hline $\mathbf{A 2}$ & EC:DEC (1:1) & 45 & 15 & 40 \\
\hline A3 & EC:DEC (1:1) & 35 & 15 & 50 \\
\hline A4 & EC:DEC (1:1) & 50 & 20 & 30 \\
\hline A5 & EC:DEC (1:1) & 40 & 30 & 30 \\
\hline B1 & Brij-L23 & 55 & 15 & 30 \\
\hline B2 & Brij-L23 & 45 & 15 & 40 \\
\hline B3 & Brij-L23 & 35 & 15 & 50 \\
\hline B4 & Brij-L23 & 50 & 20 & 30 \\
\hline B5 & Brij-L23 & 40 & 30 & 30 \\
\hline C1 & Triton X-100 & 55 & 15 & 30 \\
\hline $\mathrm{C} 2$ & Triton X-100 & 45 & 15 & 40 \\
\hline $\mathbf{C 3}$ & Triton X-100 & 35 & 15 & 50 \\
\hline $\mathrm{C4}$ & Triton X-100 & 50 & 20 & 30 \\
\hline C5 & Triton X-100 & 40 & 30 & 30 \\
\hline
\end{tabular}

\subsection{Characterization of lithium polymer electrolytes}

Thermal stability of the electrolytes was measured by thermogravimetric analysis (TGA, TGA2 Stare System, Mettler-Toledo). The temperature evaluated ranged from room temperature to $700^{\circ} \mathrm{C}$, using a heat rate of $10^{\circ} \mathrm{C} / \mathrm{min}$ under nitrogen atmosphere.

Electrochemical measurements were carried out on AUTOLAB potentiostat-galvanostat. Ionic conductivity of the polymer electrolytes was determined by AC electrochemical impedance spectroscopy (EIS) over the frequency range from $1 \mathrm{mHz}$ to $1 \mathrm{MHz}$ with an amplitude of $10 \mathrm{mV}$. The conductivities were analyzed at room temperature. The samples were sandwiched between two stainless steel (SS) electrodes (20mm diameter) using an EL-CELL system and assembled in a dry box.

A Linear Sweep Voltammetry (LSV) technique was used to determine the electrochemical stability window of the polymer electrolytes. For this purpose, a configuration of lithium metal and lithium polymer membrane in a stainless steel cell was assembled and scanned at a $1 \mathrm{mV} \mathrm{s}^{-1}$.

\section{Results and discussions}

\subsection{Properties of the plasticizers studied}

Carbonates are the most extensively used plasticizers in polymer electrolytes due to their high solubility of lithium salts and therefore the final high ionic conductivity achieved in the electrolyte. However they present non-desirable properties such as high volatility, low electrochemical stability and reactivity with electrodes. 
Surfactants are a promising group of components due to the fact that they have a wide range of structures and properties. They have been applied in different applications but still, there are few studies in literature related to their application as plasticizers in lithium polymer electrolytes.

As explained in the experimental section, two surfactants with different characteristics have been selected to study the effect of this kind of plasticizer on the final properties of polymer electrolytes. The surfactants selected for this study are commercially available Brij ${ }^{\circledR L} 23$ (B series) and Triton® X-100 (C series). Both surfactants have ether type structures (Figure 1).

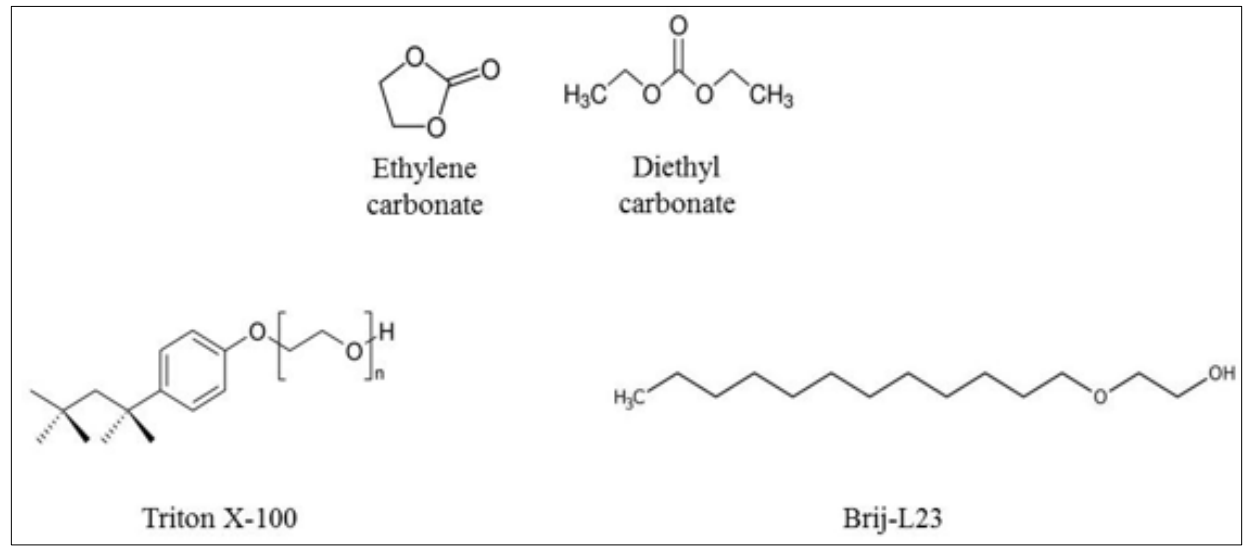

Figure 1. Structure of different plasticizer used for polymer membrane synthesis

However Triton ${ }^{\circledR}$ X-100 has several aromatic groups in its structure while Brij ${ }^{\circledR L} 23$ has an aliphatic type structure. Concerning the physicochemical properties of the surfactants (Table 2) Triton® X-100 is a viscous liquid at room temperature with a molecular weight of $625 \mathrm{~g} \mathrm{~mol}^{-1}$ whereas Brij®L23 is a solid type surfactant at room temperature, with a higher molecular weight of $1199.5 \mathrm{~g} \mathrm{~mol}^{-1}$. For comparison purposes, polymer electrolytes with the same composition have been prepared with the commonly used plasticizer, organic carbonates, specifically a mixture of EC: DEC (1/1). This mixture is a low viscosity liquid with the molecular weights of the components being $88.1 \mathrm{~g} \mathrm{~mol}^{-1}$ for ethylene carbonate (EC) and $118.1 \mathrm{~g} \mathrm{~mol}^{-1}$ for diethyl carbonate (DEC).

Table 2. Properties of different plasticizer used for polymer membrane synthesis

\begin{tabular}{|c|c|c|c|}
\hline Plasticizer & EC/ DEC & Triton X-100 & Brij-L23 \\
\hline Appearance $\cong \mathbf{2 5}^{\mathbf{0}} \mathbf{C}$ & Solid/liquid & $\begin{array}{c}\text { Liquid, clear to slightly } \\
\text { hazy }\end{array}$ & Solid \\
\hline $\begin{array}{c}\text { Molecular weight } \\
\left(\mathbf{g ~ m o l}^{\mathbf{1})}\right.\end{array}$ & $88.1 / 118.1$ & 625 & 1199.5 \\
\hline
\end{tabular}

The effect of plasticizer properties on the behavior of lithium polymer electrolytes will be discussed in the following section.

\subsection{Influence of nature of plasticizer on properties of lithium polymer electrolytes}

\subsubsection{Thermal properties}

Heat is produced when batteries operate and overheating is one of the most common causes of failure in lithium-ion batteries. As a result, all battery components require favorable thermal stabilities, including electrolytes and separators.

Thermogravimetry analysis (TGA) (Figure 2) measurements were conducted to understand the thermal properties of pure PVdF-HFP and different lithium polymer electrolytes synthesized using different type of surfactants as a plasticizer. The polymer membrane composition of 55\% polymer, $15 \%$ 
lithium salt and $30 \%$ plasticizer was selected for the thermal study. The same composition was used using organic carbonates as a reference membrane for the purpose of comparison. As can be seen in Figure 2 the PVdF-HFP polymer (curve a) does not show any degradation up to temperatures higher than $450^{\circ} \mathrm{C}$. However, the lithium polymer electrolytes synthesized display a different thermal behavior. At lower temperatures, within the range of $100-400^{\circ} \mathrm{C}$, thermal decomposition of the lithium salt and different plasticizers is produced. As can be seen, the organic carbonates (curve b) show an abrupt loss of weight taking place between $125-200^{\circ} \mathrm{C}$. In the case of surfactants, thermal decomposition is more gradual starting at $200^{\circ} \mathrm{C}$ and ending at $400^{\circ} \mathrm{C}$. If the behavior of the two different surfactants Brij®L23 (c curve) and Triton ${ }^{\circledR}$ X-100 (d curve) are analyzed a similar thermal decomposition can be observed for both of them, with that of Brij®L23 being slightly more abrupt than that of Triton® X-100. The different properties described above for the two different surfactants do not show a large impact on their thermal behavior in lithium polymer electrolytes. Finally, thermal decomposition of the PVdF-FHP can be observed at a temperature of around $500^{\circ} \mathrm{C}$. Results showed that the use of surfactants as plasticizers improves thermal stability of the lithium polymer electrolytes studied in comparison with polymers electrolytes based on organic carbonates as a plasticizer. This result is an interesting approach for improving battery safety.

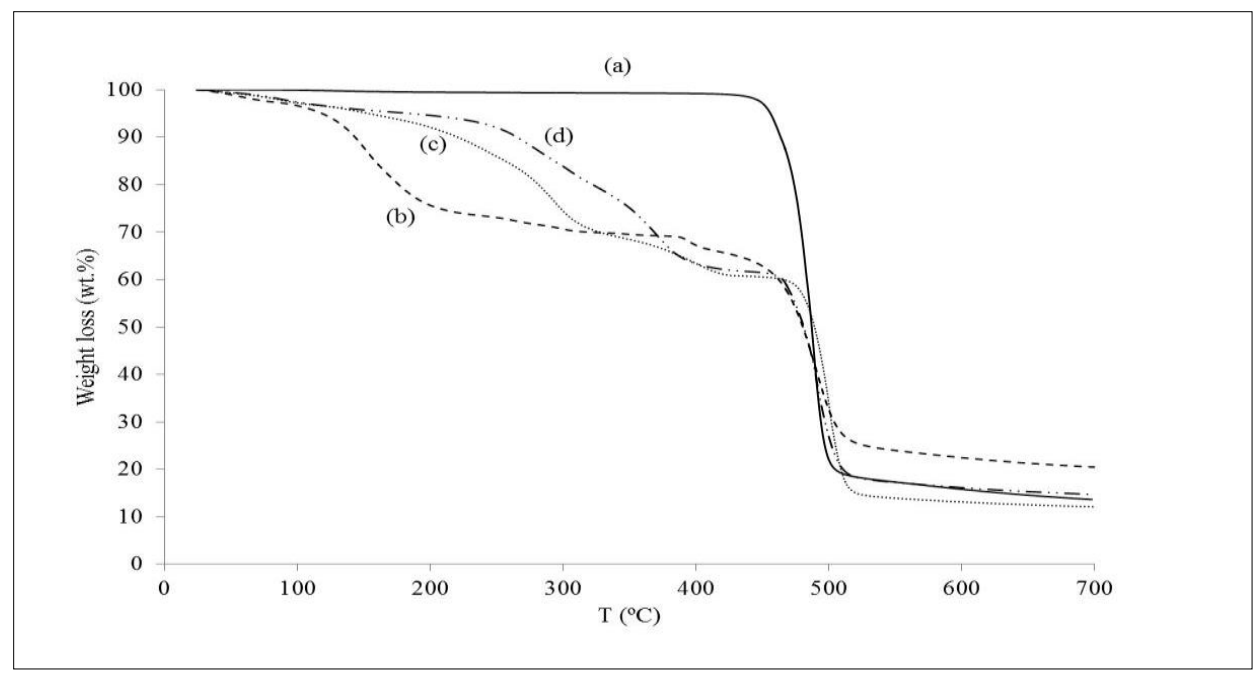

Figure 2. Thermogram of (a) pristine polymer, (b) A, (c) B and (d) C

\subsubsection{Ionic conductivity}

Ionic conductivity is an important parameter for polymer electrolytes; the higher the better and the closer to that of the liquid electrolyte value is desired. The conductivity mechanism in a gel-plasticized polymer membrane occurs through coupling between segmental motion of the polymer and ions. Ionic conduction in gel/plasticized polymer electrolytes results from ion diffusion through their free volumes, so it is important that lithium salts are dispersed in polymers at molecular level. The influence of plasticizers on the plasticized polymer electrolyte depends highly on the specific nature of the plasticizer, such as dielectric constant, viscosity, polymer-plasticizer interaction and ion-plasticizer coordination [18].

In this section, the effect of selected surfactants vs organic carbonates on ionic conductivity was studied. For that reason, lithium polymer electrolytes with different compositions were synthesized with the different plasticizers and the effect of different parameters such as plasticizer content, salt content and the plasticizer structure and molecular weight on the ionic conductivity was analyzed. Table 3 shows the results of ionic conductivity obtained using different surfactants as plasticizers (series B and C) and compared to organic carbonates (series A) when the composition of the plasticizer was varied. 
Table 3. Ionic conductivity values of polymer membranes obtained with different amounts of plasticizer

\begin{tabular}{|c|c|}
\hline Sample & $\begin{array}{c}\text { Ionic conductivity } \\
\text { (at room temperature) } \\
\left(\mathrm{S} \mathrm{cm}^{-1}\right)\end{array}$ \\
\hline A1 & $9.510^{-7}$ \\
\hline A2 & $2.110^{-6}$ \\
\hline $\mathbf{A 3}$ & $4.610^{-5}$ \\
\hline A4 & $6.010^{-5}$ \\
\hline A5 & $1.410^{-5}$ \\
\hline B1 & $2.710^{-7}$ \\
\hline B2 & $1.310^{-6}$ \\
\hline B3 & $2.310^{-6}$ \\
\hline B4 & $1.610^{-6}$ \\
\hline B5 & $1.910^{-5}$ \\
\hline C1 & $2.410^{-8}$ \\
\hline $\mathrm{C} 2$ & $1.410^{-7}$ \\
\hline $\mathrm{C3}$ & $2.510^{-7}$ \\
\hline $\mathrm{C4}$ & $1.910^{-6}$ \\
\hline C5 & $4.610^{-6}$ \\
\hline
\end{tabular}

A maximum plasticizer amount of 50wt. $\%$ and maximum salt content of $30 \mathrm{wt} . \%$ were selected to obtain polymer electrolytes with appropriate mechanical stability. From the values observed, it can be deduced that the lithium polymer electrolytes with the highest conductivity are the ones synthesized using organic carbonated as plasticizers (value comprised between $9.5 \times 10^{-7}-4.6 \times 10^{-5} \mathrm{~S} \mathrm{~cm}^{-1}$ ). If the two different surfactants are compared, it can be observed that the polymer electrolytes with Brij® L23 show higher ionic conductivity values $\left(2.7 \times 10^{-7}-1.9 \times 10^{-5} \mathrm{~S} \mathrm{~cm}^{-1}\right)$ than the ones obtained using Triton ${ }^{\circledR} \mathrm{X}-100$ $\left(2.4 \times 10^{-8}-4.6 \times 10^{-6} \mathrm{~S} \mathrm{~cm}^{-1}\right)$. The trend of ionic conductivity with plasticizer content is shown in Figure 3 .

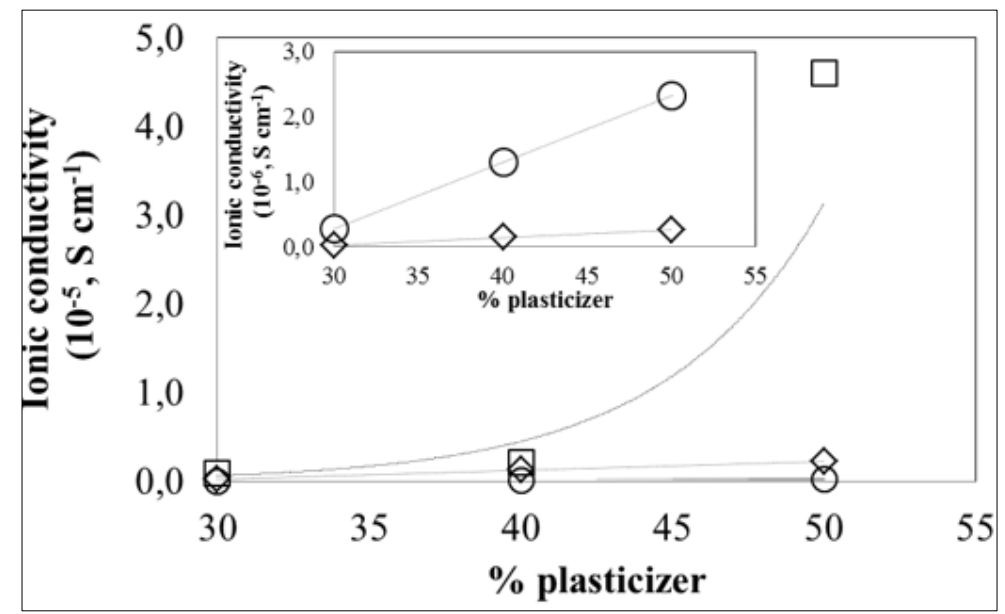

Figure 3. Tendency of ionic conductivity with plasticizer content in different plasticizer studied: $(\square)$ organic carbonates; $(0)$ BrijL23 and $(\diamond)$ Triton X-10 
In general, it can be deduced that the higher the plasticizer content, the higher the ionic conductivity obtained. This effect was observed for all lithium polymer electrolytes obtained independently of the type of surfactant and a plasticizer such as organic carbonates. In the case of Triton ${ }^{\circledR} \mathrm{X}-100$ plasticizer, ionic conductivity increases 5.8 times when the relative composition varies from 30 to $40 \%$. When the composition varies from 30 to $50 \%$ the ratio of increase is 10.5 . The same behavior is obtained when Brij®L23 is used. Ionic conductivity increases 4.8 and 8.5 times when the quantity of plasticizer moves from 30 to $40 \%$, and 30 to $50 \%$, respectively.

However, the trend of the increase in ionic conductivity is different for surfactants in comparison with organic carbonates. If organic carbonates are used, the increase of plasticizer content produces an increase of ionic conductivity in an exponential way (Figure 3). However, when surfactants are used, independently of their structure and molecular weight the increase in ionic conductivity with plasticizer content shows the linear trend. This fact is related to the different behavior of both groups of the plasticizers inside the polymer host. On the one hand, the smaller molecular size of organic carbonates in comparison with non-ionic surfactants studied could explain that. These small molecules could invade the polymer host more easily and decrease the cohesive interaction between the polymer chains, giving rise to increased mobility of the chains and ion transport $[19,20]$. On the other hand, the liquid nature of organic carbonated and the high solubility of them in $\mathrm{LiPF}_{6}$ could promote the creation of extra pathways for the ions in carbonate-based electrolytes in comparison to surfactant-based ones [21].

In Figure 4, the trend of ionic conductivity with salt content in the different plasticizer is studied. To this end, the amount of plasticizer was fixed at $30 \%$ and the amount of Li salt was varied for polymer electrolytes. In the case of Triton ${ }^{\circledR}$ X-100 with $20 \%$ salt content, there is an increase of 83 times in ionic conductivity value, in comparison with the one obtained with $15 \%$ of $\mathrm{Li}$ salt in the composition. When salt content is increased to $30 \%$, this is an increase of 190 times. In the case of BrijßL23 plasticizer, increase in conductivity was 18 times higher with $20 \%$ of the salt in the membrane composition and 70 times higher for $30 \%$ of the salt in the membrane composition, in comparison with the ionic conductivity of the sample with $15 \%$ of Li salt on the final composition. The content of $30 \%$ of the salt produced an increase of 44 times the conductivity in comparison with the reference sample.

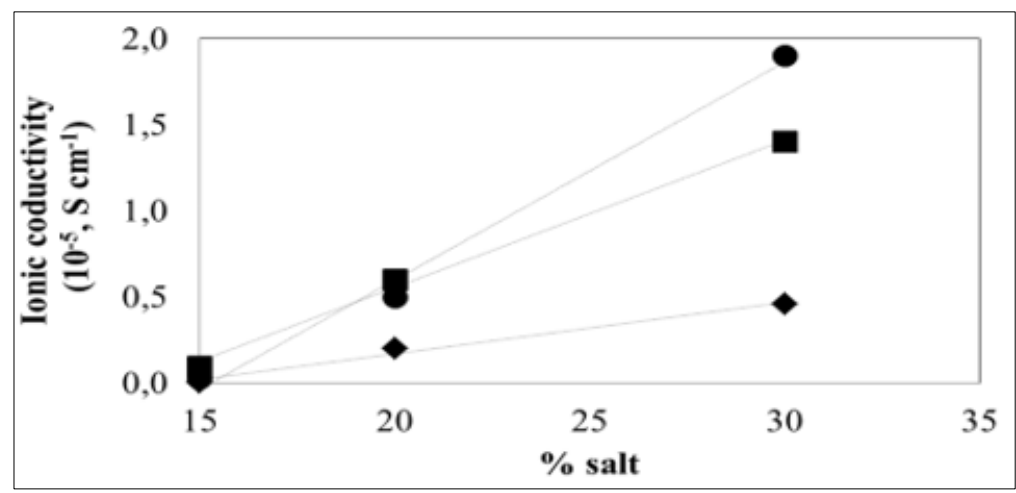

Figure 4. Tendency of ionic conductivity with salt content in different plasticizer studied: $(\bullet)$ organic carbonates $(\bullet)$ BrijL23 and $(\diamond)$ Triton X-100

In this case, the same trend was observed independently of the plasticizer used. A linear increase in ionic conductivity was observed for both surfactants and also for organic carbonates. The linear trend observed this time for organic carbonates could be explained by the possible formation of immobile aggregated species when salt amount is increased and plasticizer content is fixed, producing a lower increase of conductivity in this case [3]. However, if the two types of surfactants are compared differences can be observed in the ionic conductivity values obtained. Polymer electrolytes with Brij ${ }^{\circledR L} 23$ show higher ionic conductivity and the values obtained are similar to the ones obtained for organic carbonate based polymer electrolytes. 
Finally, the comparison of ionic conductivity between electrolytes has been made from the point of view of the nature of the plasticizer. For that purpose different membranes with the same Li salt amount and different plasticizer content were compared. In Figure 5 it can be observed that surfactant Brij®L23 gives polymer electrolytes with higher conductivity in comparison with those obtained with Triton ${ }^{\circledR} \mathrm{X}$ 100. If surfactant properties are analyzed (Table 2) Brij®L23 has a higher molecular weight than Triton® $\mathrm{X}-100$ (1199 vs $625 \mathrm{~g} \mathrm{~mol}^{-1}$ ) when both solid and a viscous liquid, respectively, at room temperature. However, the polymer electrolytes with Brij ${ }^{\circledR L} 23$ show higher ionic conductivities, indicating that molecular weight is not the only parameter to take into account in the explanation of ionic conductivity values of non-ionic surfactant based lithium polymer electrolytes studied [13,22]. If the structure of the two surfactants is compared (Figure 1) it can be observed that Brij®L23 shows linear aliphatic structure vs Triton ${ }^{\circledR} \mathrm{X}-100$ which shows aromatic type functional groups.

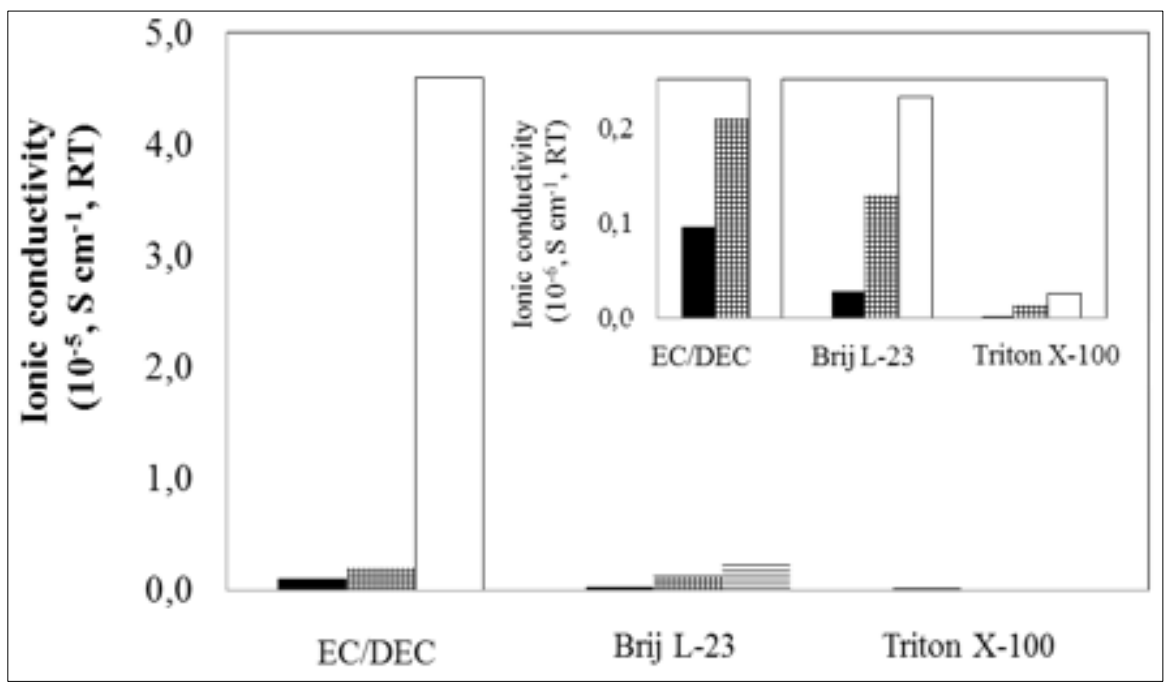

Figure 5. Influence of plasticizer type on ionic conductivity of polymer membranes with the following compositions: (-) 55\% polymer/15\% salt/ $30 \mathrm{wt} \%$ of plasticizer; ( $⿴ 囗 十) 55 \%$ polymer/ $15 \%$ salt/ $40 \mathrm{wt} . \%$ plasticizer; (固) $55 \%$ polymer $/ 15 \%$ salt/ $50 \mathrm{wt} . \%$

An explanation of the better ionic conductivities in lithium polymer electrolytes using Brij®L23 surfactant could be focused on the linear structure of this surfactant. It has been described previously that the ethylene oxide units of plasticizers could offer a high donor number for alkali metals, so the Liions can easily form a coordination linkage with them. With this coordination linkage ( $\mathrm{Li}-\mathrm{O})$ forming and breaking, Li-ions can jump along the surfactant chains to achieve ion transport. Besides, plasticizer with high chain flexibility owing to the low rotational energy barrier between oxygen and methylene, facilitates the transport of Li-ions. Based on this phenomena, the aliphatic structure of BrijßL23 could show higher chain flexibility than the aromatic type structure of Triton ${ }^{\circledR} \mathrm{X}-100$, explaining the higher ionic conductivity values observed for polymer electrolytes with Brij®L23 [23].

\subsubsection{Electrochemical stability}

Finally, the electrochemical stability of the lithium polymer electrolytes was studied using linear sweep voltammetry measurements at a scanning rate of $1 \mathrm{mV} / \mathrm{s}$. For this purpose, lithium polymer electrolytes with $55 \%$ of the polymer, $15 \%$ of lithium salt and $30 \%$ of plasticizer were selected.

As can be seen in Figure 6, the polymer membrane which contains organic carbonates as a plasticizer shows electrochemical decomposition at around $4.2 \mathrm{~V}$. In contrast, the polymer electrolytes synthesized with surfactant show a very high stability in a wide voltage window, higher than $5 \mathrm{Vvs} \mathrm{Li} / \mathrm{Li}^{+}$. In this case, both types of surfactant show the same behavior independently of their molecular weight and 
structure. The use of surfactants provides the lithium polymer electrolytes with a high electrochemical stability in comparison to commonly used organic carbonate-based plasticizers.

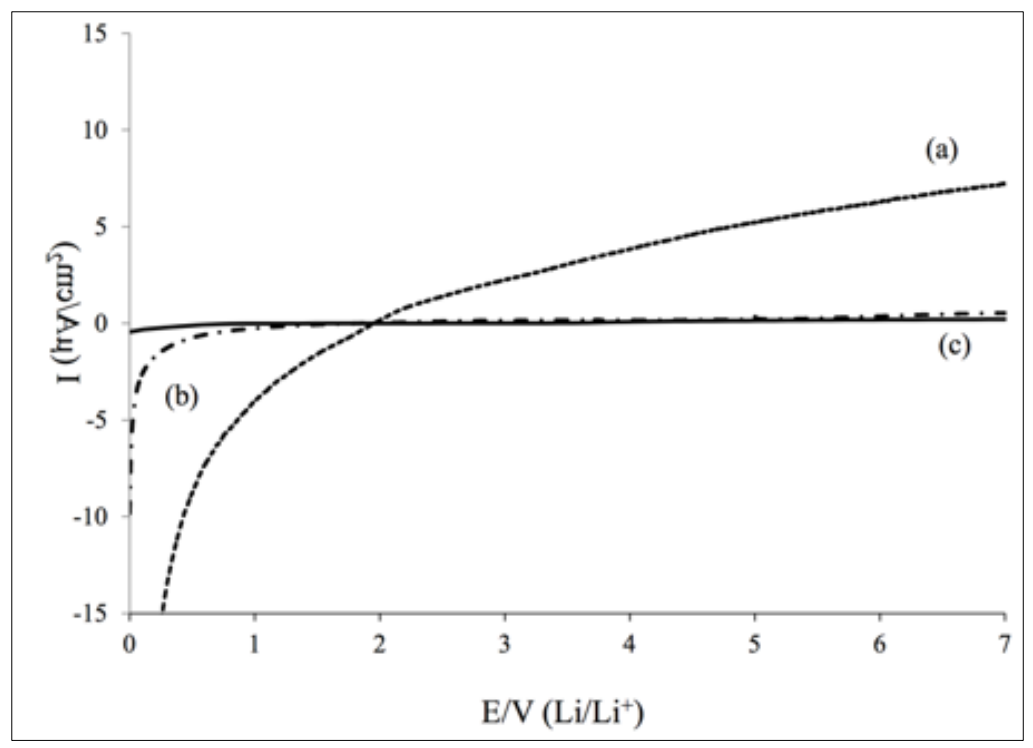

Figure 6. Linear sweep voltammetry spectra of (a) A, (b) B, (c) C

This result addresses surfactants as a promising group to be used as plasticizers for the next generation high voltage lithium-ion batteries. They can work under high voltage conditions without any degradation in the polymer electrolyte.

\section{Conclusions}

In this paper, two different types of non-ionic surfactants (Brij ${ }^{\circledR} L 23$ and Triton $\left.{ }^{\circledR} \mathrm{X}-100\right)$ with different molecular weight and structure have been studied as a plasticizer in lithium polymer electrolytes and have been compared with the commonly used plasticizer, organic carbonates. For this study, it can be concluded that the surfactants studied present thermal degradation at higher temperatures than organic-based carbonates and that decomposition is more gradual. With regards to ionic conductivity, the highest ionic conductivity was obtained using polymer electrolytes with organic carbonate-based plasticizers. If the two different non-ionic surfactants selected for the study are compared, higher ionic conductivities were obtained for samples with Brij®L23 than those with Triton® $\mathrm{X}-100$. An increase in ionic conductivity was observed for all the plasticizer studied with the amount of plasticizer. However, in the case of organic carbonates, the trend between the two parameters is exponential and it is linear in the case of the surfactant. In the case of variation of ionic conductivity with the amount of salt, an increase was observed for all samples but the trend, in this case, was linear for all the plasticizers.

The higher ionic conductivity obtained with Brij®L23 in comparison to Triton® X-100 could be associated with the linear structure of Brij ${ }^{\circledR L} 23$ in contrast to the aromatic structure of Triton ${ }^{\circledR}$ X-100 which facilitates chain flexibility and therefore the ability of ion transport.

Finally, polymer electrolytes synthesized with surfactant present a very high stability in a wide voltage window, higher than $5 \mathrm{Vvs} \mathrm{Li} / \mathrm{Li}^{+}$, in contrast to the ones synthesized with organic carbonates which decompose at $4.2 \mathrm{~V}$. In this case, both types of non-ionic surfactants studied display the same behavior independently of their molecular weight and structure. The higher thermal and electrochemical stability observed for the non-ionic surfactant based polymer electrolytes studied indicates that this type of surfactant could be promising plasticizers for the use on lithium polymer electrolytes, especially for high voltage lithium-ion batteries. 
Acknowledgments: This research was funded by the Centro de Desarrollo Tecnológico Industrial-CDTI (ALMAGRID Project- CER-20191006) and by the Instituto Valenciano de Competitividad EmpresarialIVACE-FEDER (MATER Project- IMDEEA/2019/48)

\section{References}

1.MA, J., CHEN B., WANG L., CUI G., Progress and prospect on failures mechanism of solid-state lithium batteries, Journal Power Sources, 392, 2018, 94-115.

2.PARK H.E., HONG C.H., YOON W. Y., The effect of internal resistance on dendritic growth on lithium metal electrodes in the lithium secondary batteries, Journal Power Sources, 178, 2008, 765-768. 3.CHEN S., WEN K., FAN J., BLANDO Y., GOLBERG D., Progress and future prospects of highvoltage and high-safety electrolytes in advanced lithium batteries: from liquid to solid electrolytes, Journal of Materials Chemistry A, 6, 2018, 11631

4.L. LONG, S. WANG, M. XIAO, Y. MENG, Polymer electrolytes for lithium polymer batteries, Journal of Materials Chemistry A, 4, 2016, 10038-10069

5.M. ARMAND, The history of polymer electrolytes, Solid State Ionics, 69, 1994 309-319

6.MS. LIANG, W. YAN, X. WU, Y.ZHANG, Y. ZHU, H. WANG, Gel polymer electrolytes for lithium ion batteries: Fabrication, characterizqation and performance, Solid State Ionics, 318, 2018, 2-18

7.H. BEN YOUCEF, O. GARCIA-CALVO, N. LAGO, S. DEVARAJ, M. ARMAND, Cross-linked solid polymer electrolyte for all-solid-state rechargeable lithium batteries, Electrochimica Acta, 220, 2016, 587-594

8.B. WANG, H. LOU, H. XU, J. ZHAO, Q. WANG, Q. SHI, Y. DENG, High voltage, solvent-free solid polymer electrolyte based on a star-comb PDLLA-PEG copolymer for lithium ion batteries, RSC Advances, 8, 2018, 6373-6380

9.X QIAN, N. GU, Z. CHENG, X. YANG, E. WANG, S. DONG, Plasticizer effect on the ionic conductivity of PEO-based polymer electrolyte, Materials Chemistry and Physics, 74, 2002, 98-103 10.K.W. OH, J.H. CHOI, S.H. KIM, Improvement of mechanical and electrical of poly(ethylene glycol) and cyanoresin based polymer electrolytes, Fibers and Polymers, 7, 89-94 (2006).

11.A.M. STEPHAN, K.S. NAHM, Review on composite polymer electrolytes for lithium batteries, Polymer 47, 2006, 5952-5964.

12.D. LIM, J. MANUEL, J. AHN, J. KIM, P. JACOBSSON, A. MATIC, J.K. HA, K.K. CHO, K. KIM, Polymer electrolytes based on poly(vinylidene fluoride-co-hexafluoropropylene) nanofibrous membranes containing polymer plasticizers for lithium batteries, Solid State Ionics, 225, 2012, 631-635. 13.S. RAJENDRAN, V. SHANTI BAMA, A study on the effect of various plasticizers in poly(vinyl acetate)-poly(methyl methacrylate) based gel electrolytes, Journal of Non-Crystalline Solids, 356, 2010, 2764-2768.

14.E.D. GODDARD, Polymer-surfactant interaction Part I. uncharged water-soluble polymers and charged surfactants, Colloid Surfaces, 19, 1986, 255-300

15.A. BRIDDICK, P. LI, A. HUGHES, F. COURCHAY, A. MARTINEZ, R.L. THOMPSON, Surfactant and plasticizer segregation in thin poly(vinyl alcohol) films, Langmuir, 32, 2016. 864-872

16.K. DILLIP, R.N.P. CHOUDHARY, B.K. Samantaray, Materials Chemistry and Physics, 115, 557 (2009)

17.S. DAS, A. GHOSH, Effect of plasticizers on ionic conductivity and dielectric relaxation of PEOLiClO4 polymer electrolyte, Electrochimica Acta, 171, 59 (2015)

18.S. RAJENDRAN, P. SIVAKUMAR, An investigation of PVdF-PVC-based blend electrolytes with EC/PC as plasticizers in lithium battery applications, Physica B 403509 (2008)

19.W. H. MEYER, Polymer electrolytes for lithium-ion batteries, Advanced Materials, 10, 439 (1998) 20.V. PONNUCHAMY V., S. MOSSA, I. SKARMOUYTSOS, Solvent and salt effect on lithium ion solvation and contact ion pair formation in organic carbonates: a quantum chemical perspective, J. Phys. Chem. C, 122 (45) 25930-25939 (2018) 
21.M. S. S. RAJENDRAN, R. SUBADEVI, Investigations on the effect of various plasticizers in PVAPMMA solid polymer blend electrolytes, Materials Letters, 58, 2004, 641-649

22.ALLEN D. GODWIN, Applied Polymer Science: 21st Century, 157 (2000)

23.L. JIN, F. AHMED, T. RYU, S. YOON, W. ZHANG, Y. LEE, D. KIM, H. JANG, W. KIM, Highly conductive and flexible gel polymer electrolyte with bis(fluorosulfonyl) imide lithium salt via UV curing for Li-ion batteries, Electrolytes, 9, 2019, 139-150

$\overline{\text { Manuscript received: } 11.11 .2020}$ 